\title{
A Model Study on Accelerated Consolidation of Coir Reinforced Lateritic Lithomarge Soil Blends with Vertical Sand Drains for Pavement Foundations
}

\author{
George Varghese, Hegde Ramakrishna, A. G. Nirmal Kumar, L. Durga Prashanth, G. Santosh
}

Department of Civil Engineering, National Institute of Technology Karnataka, Surathkal, India.

Email: varghese@nitk.ac.in; yashas2all@yahoo.com

Received May $12^{\text {th }}, 2012$; revised June $10^{\text {th }}, 2012$; accepted June $24^{\text {th }}, 2012$

\begin{abstract}
Sub-grade soils of lateritic origin encountered in the construction of highway embankments in various regions of India, often comprise intrusions of soft lithomargic soils that result in large settlements during constructions, and differential settlements at later stages. This necessitates the use of appropriate soil improvement techniques to improve the load-carrying capacity of pavements. This work deals with accelerated consolidation of un-reinforced and coir-reinforced lateritic lithomargic soil blends, provided with three vertical sand drains. The load-settlement characteristics were studied for various preloads ranging from $50 \mathrm{~kg}\left(0.0013 \mathrm{~N} / \mathrm{mm}^{2}\right)$ to $500 \mathrm{~kg}\left(0.013 \mathrm{~N} / \mathrm{mm}^{2}\right)$ on soil specimens prepared in circular ferrocement moulds. It was observed that at lower preloads up to $200 \mathrm{~kg}$, across the blends, the relative increase in consolidation $\left(R_{c t}\right)$ for randomly reinforced soil with vertical drains was significantly higher than that of un-reinforced soil without vertical drains, with an average value of $124.8 \%$. Also, the $R_{c t}$ for un-reinforced soil with vertical drains was quite higher than that of un-reinforced soil without vertical drains, with an average value of $103.9 \%$. In the case of higher preloads, the $R_{c t}$ values for randomly reinforced soil with vertical drains were moderate with an average value of $30.88 \%$, while the same for un-reinforced soil with vertical drains was about $20.4 \%$. The aspect-ratio of coir fibers used was 1:275.
\end{abstract}

Keywords: Vertical Sand Drains; Accelerated Consolidation; Settlement; Coir Reinforcement; Laterite; Shedi; Lithomarge

\section{Introduction}

Construction and maintenance of pavements in waterlogged areas pose challenging problems to engineers. The defects in road sub-grades mainly arise due to poor compaction and consolidation. This is of major concern in road-works associated with submersible areas. Incorporating the use of natural fibers in soil-stabilization, along with the laying of natural fiber reinforced vertical sand drains can contribute towards strengthening of road sub-grades especially in the construction of highway embankments.

Differential settlement of sub-grade soils cause damages to pavements in many regions. The problem assumes critical importance in clayey and silty soil subgrades that have low permeability values. In such soils, the consolidation and the resultant settlements occur over a longer time-span. This work focuses on conducting extensive studies on the consolidation characteristics of weak soil sub-grades.

Natural geo-textiles made of coir or jute can be effect- tively employed in the improvement of sub-grade strength by accelerating the drainage of soil-moisture content resulting in enhanced consolidation.

The name laterite was initially suggested by Francis Buchanan [1] to describe "ferruginous, vesicular, unstratified, and porous soil with yellow ochre's due to high iron content, occurring in Malabar, India". In the district of Dakshina Kannada, and Udupi, laterite soil can be found to occur above underlying shedi soil (or fine silty soil). Laterite soil is quite stronger than shedi soil due to the higher content of oxides of iron, while shedi soils are characterized by low bearing strengths under moist conditions.

In India, lithomargic clays are often found to occur at depths of $1-3$ meters below the top lateritic outcrops throughout the western coastal areas extending from Trivandrum to Mumbai, and also in the areas adjoining the Deccan Plateau. Shedi soil is the name given to the locally available whitish, pinkish or yellowish lithomargic soils with high silt content, and low bearing strengths. 
These soils are formed by weathering of soils in tropical regions, and contain hydrated alumina, primary silicates, and kaolinite. Lithomargic soils comprise 50\% - 90\% lateritic constituents, while soils with $25 \%$ - 50\% laterite content are known as lateritic lithomarges.

\section{Scope and Objectives of the Present Study}

In order to attain higher bearing strengths in soft soils, it may be required to resort to accelerated consolidation during the construction stage by applying incremental loads on suitably prepared sub-grades in stages. The pore-water pressure that builds up under the overburden pressure and surcharge loads, can be released with the use of natural reinforcements especially on weak soils.

Additionally, the use of vertical drains will shorten the length of the horizontal drainage-paths, and accelerate the consolidation process. The enhanced dissipation of pore-water pressure due to the presence of natural fiber reinforcements and the overburden pressures, will result a further acceleration of the consolidation process in lateritic and shedi (L-S) soil sub-grades of embankments. The natural degradation of natural fibers after a few years [2] will not affect the strength and stability of L-S soil sub-grades due to the reason that the soil layers would have attained consolidation in the meantime.

The present work deals with investigations on loadsettlement characteristics due to accelerated consolidation of various blends of laterite and lithomargic (shedi) soils, with and without the use of reinforcements of randomly dispersed coir-fibers, and with and without the use of vertical sand drains randomly reinforced with coir. This study also incorporates an assessment of the improvement in the California Bearing Ratio (CBR) values of L-S soil, when randomly mixed with coir for soaked and un-soaked conditions.

The objectives of the present study include the following:

- To prepare blended laterite-shedi (L-S) soil comprising $25 \%$ laterite and $75 \%$ shedi soil, and to perform basic laboratory investigations such as grain size analysis, Atterberg's limits, CBR tests, tests for standard and modified compaction tests for L-S soil samples as specified by Indian Standard (IS) codes.

- To measure the load-settlement properties and consolidation of fully saturated confined and un-reinforced L-S soil without the use of vertical drains for soil samples drained at the top and bottom.

- To measure the load-settlement properties and consolidation of fully saturated confined and un-reinforced L-S soil with the use of 3 vertical drains.

- To measure the load-settlement properties and consolidation of fully saturated confined randomly rein- forced L-S soil provided with 3 vertical drains

- In the case of tests on blended L-S soils, an optimum fiber content of $1.0 \%$ of coir fiber was adopted for random reinforcement.

- The sand-drains were fabricated using sand randomly reinforced with $1 \%$ of coir fibers. Loosely-woven jute fabric stitched at the seams was used in the installation of sand-drains of $10 \mathrm{~cm}$ diameter.

- The results were compared with the same for $50 \%$ laterite $+50 \%$ shedi soil samples [3], and $100 \%$ shedi [4] obtained in similar studies.

\section{Literature Review}

Studies on the stability of loaded footings on reinforced soil using natural "iko" vegetable fibers, reported by Akinumusura and Akinbolade [5] indicated that a significant improvement in soil strength could be achieved.

Investigations on using vertical drains made of natural fiber such as jute and coir for soil improvement simulating field conditions, was reported by Lee et al. [6]. The studies revealed that the axial filter permeability of fiber drains was higher than $10^{-5} \mathrm{~m} / \mathrm{sec}$ for consolidation pressures of up to $400 \mathrm{kN} / \mathrm{m}^{2}$.

Similar investigations in the field of application of coir-fibers $[7,8]$ highlighted the advantages in the use of natural fibers for stabilization of embankments associated with the use of fiber-reinforced vertical drains.

Stapelfeldt [9] reported that preloading and the use of vertical drains, can enhance the shear strength of the soil, resulting in reduced soil compressibility, and permeability prior to construction, preventing differential settlements.

Comparative studies on soft clay soils of Bangkok by Bergado et al. [10] revealed the use of compacted granular piles (CGP), and prefabricated vertical drains (PVD). The studies indicated that in the case of soils improved with PVDs, the settlement rates were higher by $30 \%$ $35 \%$ when compared to soils improved using CGPs.

It was also noticed by Gosavi et al. [11] that the inclusion of randomly distributed fibers of jute and coir, in black cotton soils, increased the CBR values of clayey sands (SW) and sandy-silt (SM) by about $96 \%$.

Terzaghi [12] provides the basic theory for such onedimensional consolidation for saturated conditions and also provides the strain formulation. The relationship between the final settlement $\left(S_{f}\right)$ and the settlement $\left(S_{t}\right)$ at time $t$ was expressed as:

$$
S_{t}=U_{v} \cdot S_{f}
$$

The expression for $U_{v}$, the average degree of consolidation at depth $z$ at any instant $t$ was given by Terzaghi [13] as, 


$$
U_{v}=1-\sum_{m=0}^{\infty}\left(2 / M^{2}\right) \exp \left(-M^{2} T_{v}\right)
$$

where $T_{v}=$ time factor (non dimensional) $=\left(C_{v} t\right) / H^{2} ; C_{v}$ $=$ coefficient of vertical consolidation $\left(\mathrm{m}^{2} / \mathrm{s}\right)=\mathrm{k} /\left(\gamma_{\mathrm{w}} m_{v}\right)$; $k=$ permeability coefficient; $m_{v}=$ coefficient of volume compressibility $=a_{v} /\left(1+e_{0}\right) ; e_{0}=$ initial void ratio; $a_{v}=$ coefficient of compressibility $=\Delta_{e} / \Delta_{\mathrm{p}} ; t=$ time in seconds; $H=$ total distance of drainage path which is equal to the thickness of the layer (in $\mathrm{m}$.) for soil subjected to top drainage, and is equal to half of the thickness of the layer (in $\mathrm{m}$ ) for soils drained at the top and the bottom. The expression for $\mathrm{M}$ is given as,

$$
M=\pi(2 m+1) / 2 \text { for } m=0,1,2 \cdots a \text {. }
$$

From the above formulation, it is evident that consolidation is dependent on the permeability of the medium. Therefore, it is expected that the use of vertical drains will have a profound effect on accelerating the consolidation process.

\section{Materials Used}

Laterite, and Shedi soil: Laterite soil (obtained from a site adjoining the newly widened National Highway-17, near NITK, Surathkal, Mangalore), and shedi soil (obtained from a road construction site close to Vidyanagara, Kulai, Mangalore), were collected in water-proof polythene bags, transported to the laboratory, and spread on flat trays of size, $1500 \mathrm{~mm} \times 900 \mathrm{~mm}$. The lumps were broken down using rammers, and the soil was sun-dried for 10 days, until the weight of soil on the trays was found to be constant, indicating that the soil was moisture-free. The laterite and shedi soil fractions were then intermixed 5 times using the technique of quartering. The basic soil properties including OMC (optimal moisture content), and MDD (maximum dry-density) were determined.

Sand: Locally available river-sand passing through $4.75 \mathrm{~mm}$ IS sieve with a coefficient of curvature $\left(C_{c}\right)$ of 0.82 , and a uniformity coefficient $\left(C_{u}\right)$ of 1.7 , was used for the preparation of vertical drains. The sand selected satisfies the general requirements of permeability and piping as suggested by Khanna and Justo [14].

Coir: In the present study, coir fibers were purchased from the local market. This comprised of brown coir fibers with aspect ratios of about 275 and an average diameter of $0.18 \mathrm{~mm}$. The average length of the fibers used in this study was maintained at $50 \mathrm{~mm}$. Rao et al. [15] suggested the use of $0.5 \%$ to $1 \%$ of coir fiber by weight of sand, and also proved that the use of fibers will restrict the lateral deformation at the peripheral areas of sand drains. Accordingly, in the present study, $1.0 \%$ of coirfiber by weight of sand was used in preparing randomly distributed fiber-reinforced vertical sand drains.

\section{Determination of Optimal Fiber Content for Soil Samples Using CBR Tests}

CBR tests were conducted as per IS 2720: Part VII (1983) [16]. with various percentages of coir fiber content randomly reinforced with $0.25 \%, 0.5 \%, 0.75 \%, 1.0 \%$, and $1.25 \%$ of coir, and the CBR values at $2.5 \mathrm{~mm}$ and $5 \mathrm{~mm}$ penetrations were noted for soaked and un-soaked soil samples. The CBR values were determined for the soil samples, and the optimum fiber contents are reported as in Table 1.

\section{Tests for Consolidation}

The test for accelerated consolidation involves several stages such as, preparation of the soil sample, soaking of specimens, loading, and installation of vertical drains and preloading of soil samples. The soil sample to be tested was prepared as mentioned above, and the water contents required to prepare soil beds at $80 \%$ MDD were determined from the compaction curves. It was decided to perform tests at moisture content lesser than the OMC in order to study the load-settlement characteristics effecttively.

\section{Experimental Setup and Methodology}

Investigations were conducted for reinforced and unreinforced soil specimens, with and without installation of vertical drains. These tests were conducted in order to evaluate the improvement in the bearing capacity due to the accelerated consolidation.

\subsection{Tests for Consolidation of Un-Reinforced Soil without Using Vertical Drains}

In order to study the compressibility and consolidation of soil sample, a ferro-cement cylindrical test mould was used, of $740 \mathrm{~mm}$ internal diameter, $850 \mathrm{~mm}$ height, and $30 \mathrm{~mm}$ wall thickness. The test mould was provided with an inlet pipe at the top and an outlet pipe at the bottom, both of $20 \mathrm{~mm}$ diameter, to permit soaking of the soil sample, and drainage of water. The test mould was placed on leveled ground.

A sand layer of $100 \mathrm{~mm}$ thickness was provided at the bottom of the Ferro-cement tank to act as a permeable layer, and was compacted to a density of $1.53 \mathrm{~g} / \mathrm{cc}$.

Table 1. Optimum fiber contents (OFC) determined for various blends.

\begin{tabular}{cccc}
\hline Sl. no & Soil Blends & OMC $(\%)$ & OFC (\%) \\
\hline 1 & $100 \%$ Shedi & 19 & 1.0 \\
2 & $25 \% \mathrm{~L}+75 \% \mathrm{~S}$ & 15 & 1.0 \\
3 & $50 \% \mathrm{~L}+50 \% \mathrm{~S}$ & 14 & 0.75 \\
\hline
\end{tabular}


Above this layer, a jute textile was provided to act as a separator. Over this, three layers of the soil sample, each of $200 \mathrm{~mm}$ thickness, were placed and compacted to $80 \%$ of the MDD. The soil and the sand layers were compacted to the desired thickness, and respective densities using a steel rammer (of $885 \mathrm{~mm}$ height, $140 \mathrm{~mm}$ diameter, and $11.5 \mathrm{~kg}$ weight) and a wooden rammer (of $870 \mathrm{~mm}$ height, $40 \mathrm{~mm}$ diameter, and $1.17 \mathrm{~kg}$ weight). On top of the three layers of compacted soil sample, a layer of jute textile was placed. A layer of sand of 100 $\mathrm{mm}$ thickness compacted to a density of $1.53 \mathrm{~g} / \mathrm{cc}$ was provided at the top, to act as level-surface for the application of preloads.

The soil sample in the cylindrical test mould possesses the same characteristics as mentioned in the sections above. A flat surface made of treated perforated plywood (of $730 \mathrm{~mm}$ diameter, and $12 \mathrm{~mm}$ thickness) was provided above the sand layer. A schematic diagram of the test set up is shown in Figure 1. The details of the components used in this experiment are listed below:

1) Ferro-cement mould of cylindrical shape

2) $100 \mathrm{~mm}$ thick layer of sand at the bottom

3) Bottom layer of jute-textile as a separator

4) Three layers of soil, each of $200 \mathrm{~mm}$ thickness

5) Top layer of jute-textile as a separator

6) Top layer of sand of $100 \mathrm{~mm}$ thickness

7) Loading platform of treated plywood

8) Standard steel weights

9) Dial gauges of $0.01 \mathrm{~mm}$ least count

10) Water inlet

11) Water outlet

\subsection{Tests on Consolidation of Un-Reinforced Soil Using Three Vertical Drains}

The test setup and procedure for test on consolidation of un-reinforced soil sample are the same as that explained above. A Ferro-cement cylindrical test mould with vertical drains of $100 \mathrm{~mm}$ diameter and $600 \mathrm{~mm}$ height is installed in a triangular pattern such that the center to center distance between the adjacent drains is $350 \mathrm{~mm}$. This arrangement is considered to be more effective as it is expected to result in uniform consolidation between the drains due to the uniform center to center distances, when compared to vertical drains installed in a square pattern. The radius of influence $(R)$ of a vertical drain depends upon the spacing $(S)$ between drains. In the case of cylindrical drains installed in triangular pattern the radius of influence $(R)$ can be computed from the empirical formula,

$$
R=0.546 \times S
$$

Thus for vertical drains of $100 \mathrm{~mm}$ diameter and center to center spacing of $350 \mathrm{~mm}$ between the drains, the

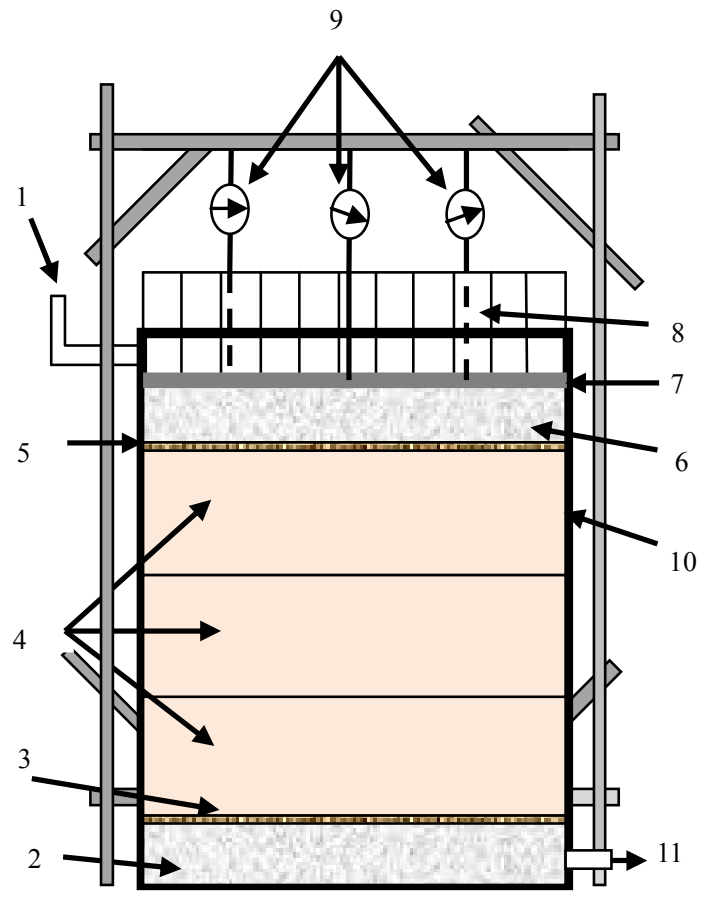

Figure 1. Schematic diagram of the test setup without vertical drains.

radius of influence can be obtained as $190 \mathrm{~mm}$ based on Equation (4). The vertical drains of $600 \mathrm{~mm}$ height were installed with the help of sampling tubes of $100 \mathrm{~mm}$ diameter inserted into sleeves made of jute fabric. See Figure 2, Figures 3(a)-(d) provide a clear view of the installation of vertical drains.

The sampling tubes enclosed in the jute sleeves, were then filled in two layers with sand randomly mixed with $1 \%$ of coir fibers by weight of sand for a height of 200 mm by compacting with a wooden tamping tool with 15 blows per layer to obtain a compacted density of 1.08 $\mathrm{g} / \mathrm{cc}$. The tubes were gradually withdrawn when each layer of soil sample of $100 \mathrm{~mm}$ was compacted. Smears developed due to the disturbance to the soil while installing vertical drains, can result in reduced soil permeability around the smear zone, restricting the rate of consolidation. However, in this investigation, since the vertical drains were installed in a simultaneous build-up procedure, the smear effects are assumed to be negligible.

\section{Jute Textiles}

Woven jute textile fabric of $600 \mathrm{~g}$ per sq.m and $1.43 \mathrm{~mm}$ thickness was used in fabricating the sleeves for the vertical drains. The properties of jute textiles used in this study are given in Table 2. Mild steel sleeves of $100 \mathrm{~mm}$ average diameter and $600 \mathrm{~mm}$ height were used to buildup the vertical drains to span the entire depth of laterite soil tested. 


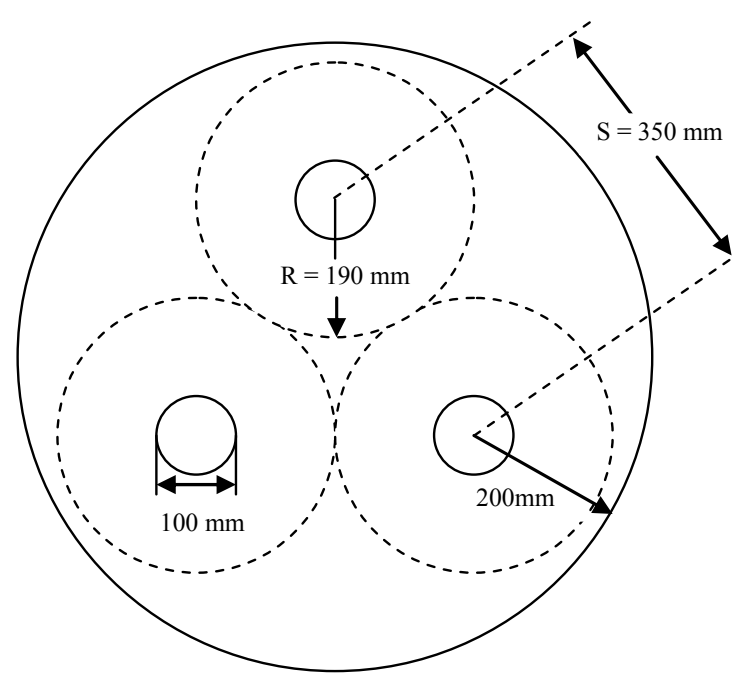

Figure 2. Influence zone for triangular pattern of drains (Stapelfeldt, 2006).

\subsection{Tests on Consolidation of Randomly Reinforced Soil Using Three Vertical Drains}

In this part of the experiment, the soil used in the test mould was randomly reinforced using coir. The optimum fiber content of $1.0 \%$ by weight of soil was adopted in these tests. The overall experimental setup remains the same as explained above.

\section{Results}

\subsection{Soil Blend Type: $50 \% \mathrm{~L}+\mathbf{5 0 \%} \mathrm{S}$}

The load-settlement details are discussed below for unreinforced soil samples without vertical drains (UR), unreinforced soil samples with vertical drains (UR-VD), and reinforced soil samples with vertical drains (RRVD).

\subsubsection{Settlement for UR $(50 \% \mathrm{~L}+\mathbf{5 0} \% \mathrm{~S})$}

Figure 4(a) provides details on the load-settlement characteristics for un-reinforced soils comprising $50 \%$ laterite and $50 \%$ shedi soil. Also, Table 3(a) provides details on the coefficient of consolidation $\left(C_{v}\right)$ for various preloads for the soil sample tested. It can be observed that during the initial stages of loading using preloads of $50 \mathrm{~kg}, 100$ $\mathrm{kg}, 150 \mathrm{~kg}, 200 \mathrm{~kg}$ and $250 \mathrm{~kg}$, the compaction of soil is considered to have taken place. This can be visualized from the corresponding increase in the rate of compacttion in the above table. Thereafter, the rate of compaction for preloads of $300 \mathrm{~kg}$ to $500 \mathrm{~kg}$ shows a decreasing trend, indicating the commencement of the consolidation process.

\subsubsection{Settlement for UR-VD $(50 \% \mathrm{~L}+50 \% \mathrm{~S})$}

Figure 4(b) provides details on the load-settlement char-

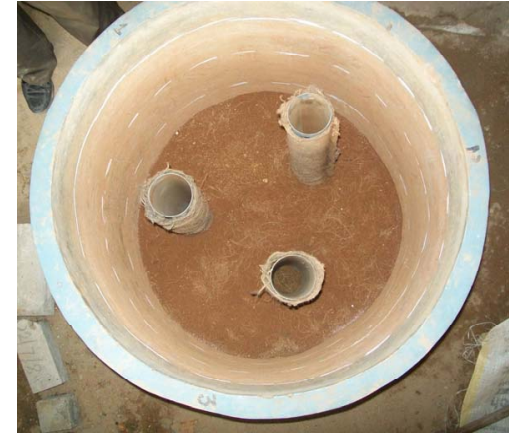

(a)

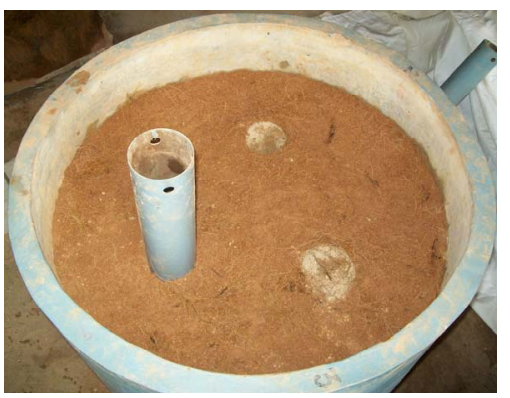

(b)

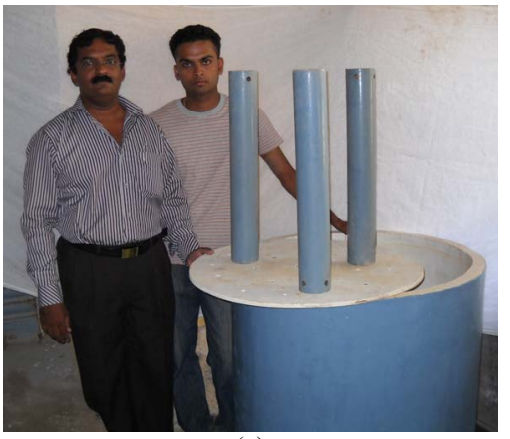

(c)

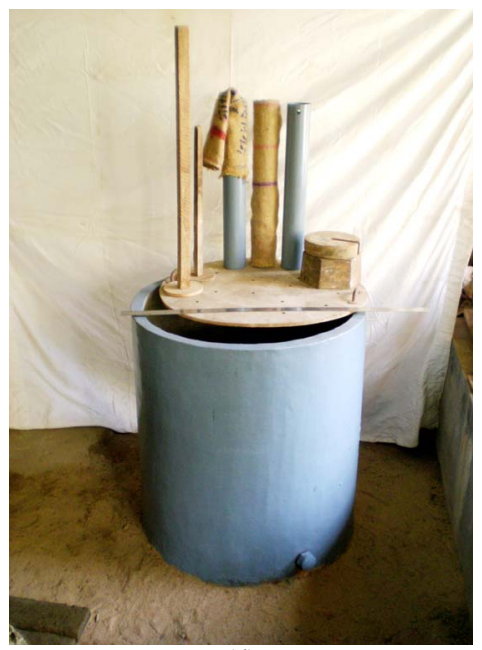

(d)

Figure 3. (a) Installation of vertical drains; (b) Removal of casing for the third vertical drain; (c) Test mould with accessories for vertical drains; (d) Test mould with accessories for vertical drains. 


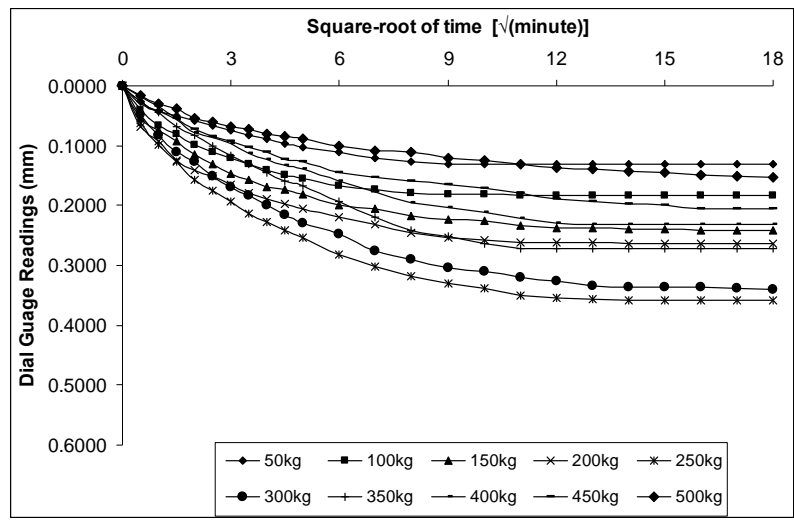

(a)

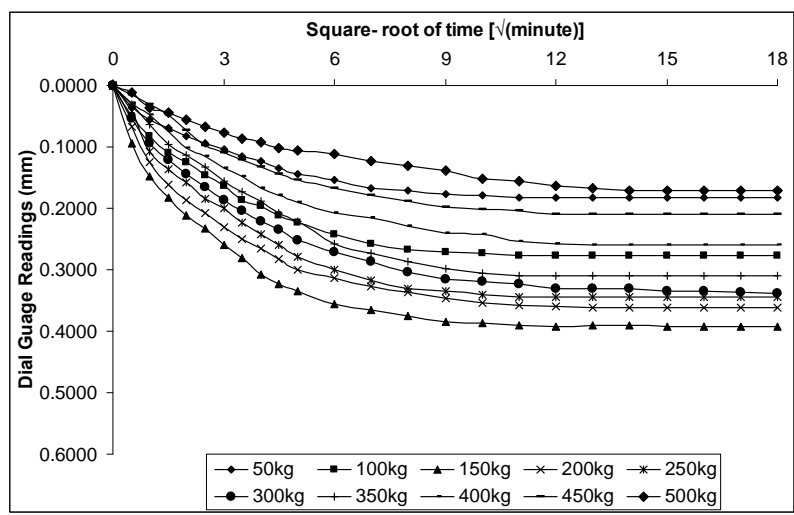

(b)

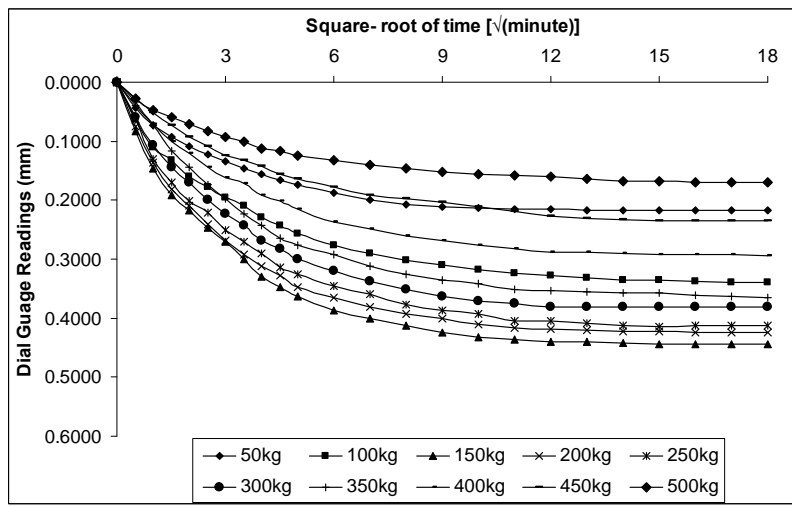

(c)

Figure 4. (a) Load-settlement: UR (50\% L + 50\% S) soils; (b) Load-settlement: UR-VD $(50 \%$ L $+50 \%$ S) soils; (c) Load-settlement: RR-VD (50\% L + 50\% S) soils.

Table 2. Properties of jute textiles used in this investigation.

\begin{tabular}{lc}
\hline Property & Woven Type \\
\hline Weight, gm per sq.m & 600 \\
Thickness, mm & 1.43 \\
Wrap $\times$ Weft per 100 sq. $\mathrm{mm}$ & $28 \times 34$ \\
\hline
\end{tabular}

acteristics for un-reinforced vertically drained soils comprising $50 \%$ laterite and $50 \%$ shedi soil. Table $3(\mathbf{b})$ pro-
Table 3. (a) $C_{v}$ values: UR (50\% $\left.\mathrm{L}+50 \% \mathrm{~S}\right)$ soils; (b) $C_{v}$ values: UR-VD (50\% L + 50\% S) soils; (c) $C_{v}$ values: RR-VD $(50 \% \mathrm{~L}+50 \% \mathrm{~S})$ soils.

(a)

\begin{tabular}{cc}
\hline \multicolumn{2}{c}{ Co-efficient of consolidation $\boldsymbol{C}_{\boldsymbol{v}}$} \\
\hline Preload (kg) & $\boldsymbol{C}_{\boldsymbol{v}}$ \\
\hline 50 & 1.2351 \\
100 & 1.2966 \\
150 & 1.3365 \\
200 & 1.4565 \\
250 & 1.6830 \\
300 & 1.5428 \\
350 & 1.3644 \\
400 & 1.2977 \\
450 & 1.2711 \\
500 & 1.1923 \\
\hline
\end{tabular}

(b)

\begin{tabular}{cc}
\hline Co-efficient of consolidation $\boldsymbol{C}_{\boldsymbol{v}}$ \\
\hline Preload $(\mathbf{k g})$ & $\boldsymbol{C}_{\boldsymbol{v}}$ \\
\hline 50 & 1.0805 \\
100 & 1.4244 \\
150 & 2.0567 \\
200 & 1.7394 \\
250 & 1.5999 \\
300 & 1.5614 \\
350 & 1.4898 \\
400 & 1.1785 \\
450 & 1.1239 \\
500 & 1.1473 \\
\hline
\end{tabular}

(c)

\begin{tabular}{cc}
\hline \multicolumn{2}{c}{ Co-efficient of consolidation $\boldsymbol{C}_{\boldsymbol{v}}$} \\
\hline Preload $(\mathbf{k g})$ & $\boldsymbol{C}_{\boldsymbol{v}}$ \\
\hline 50 & 1.0894 \\
100 & 1.4241 \\
150 & 2.0784 \\
200 & 1.9932 \\
250 & 1.6400 \\
300 & 1.6296 \\
350 & 1.4895 \\
400 & 1.2707 \\
450 & 1.1574 \\
500 & 1.0894 \\
\hline
\end{tabular}


vides details on the coefficient of consolidation $\left(C_{v}\right)$ for various preloads for the soil sample tested. In this case, it can be seen that during the initial stages of loading, as in the case of preloads of $50 \mathrm{~kg}, 100 \mathrm{~kg}$, and $150 \mathrm{~kg}$, the compaction of soil is considered to have taken place. Thereafter, the rate of compaction for preloads of $200 \mathrm{~kg}$ to $500 \mathrm{~kg}$ shows a decreasing trend, indicating the commencement of the consolidation process.

\subsubsection{Settlement for RR-VD $(50 \% \mathrm{~L}+50 \% \mathrm{~S})$}

Figure 4(c) illustrates details on the load-settlement characteristics for randomly-reinforced vertically drained soils comprising 50\% laterite and 50\% shedi soil. Table 3(c) gives details on the coefficient of consolidation $\left(C_{v}\right)$ for various preloads. It can be observed that in the initial stages of loading, the behavior of the soil is almost the same as observed in the case of UR-VD $(50 \% \mathrm{~L}+50 \% \mathrm{~S})$ soil. The rate of compaction for preloads of $200 \mathrm{~kg}$ to $500 \mathrm{~kg}$ shows decreasing trend, indicating the commencement of the consolidation process.

\subsection{Soil Blend Type: $25 \% \mathrm{~L}+\mathbf{7 5 \%} \mathrm{S}$}

\subsubsection{Settlement for UR $(25 \% \mathrm{~L}+\mathbf{7 5 \%} \mathrm{S})$}

Figure 5(a) provides details on the load-settlement characteristics for un-reinforced soils comprising $25 \%$ laterite and $75 \%$ shedi soil. Also, Table 4(a) provides details on the coefficient of consolidation $\left(C_{v}\right)$ for various preloads for the soil sample tested. Here, the compaction of soil is seen to have taken place up to preloads of $300 \mathrm{~kg}$. The rate of compaction for preloads of $350 \mathrm{~kg}$ to $500 \mathrm{~kg}$ shows a decreasing trend, indicating the commencement of the consolidation process.

\subsubsection{Settlement for UR-VD $(25 \% \mathrm{~L}+\mathbf{7 5 \%} \mathrm{S})$}

Figure 5(b) provides details on the load-settlement characteristics for un-reinforced vertically drained soils comprising $25 \%$ laterite and $75 \%$ shedi soil. Table 4 (b) provides details on the coefficient of consolidation $\left(C_{v}\right)$ for various preloads. Here, the compaction of soil is seen to have taken place up to preloads of $200 \mathrm{~kg}$. The rate of compaction for preloads of $250 \mathrm{~kg}$ to $500 \mathrm{~kg}$ shows a decreasing trend, indicating the commencement of the consolidation process.

\subsubsection{Settlement for RR-VD $(25 \% \mathrm{~L}+\mathbf{7 5 \%} \mathrm{S})$}

Figure 5(c) provides details on the load-settlement characteristics for randomly-reinforced vertically drained soils comprising 25\% laterite and $75 \%$ shedi soil. Table 4(c) provides details on the coefficient of consolidation $\left(C_{v}\right)$ for various preloads. Here too, the compaction of soil is seen to have taken place up to preloads of $200 \mathrm{~kg}$ as in the case of UR-VD $(50 \% \mathrm{~L}+50 \% \mathrm{~S})$ and UR-VD $(25 \% \mathrm{~L}+$ $75 \% \mathrm{~S})$ soils. The rate of compaction for preloads of
Table 4. (a) $C_{v}$ values: UR (25\% L $+75 \%$ S) soils; (b) $C_{v}$ values: UR-VD $\left(25 \% \mathrm{~L}+75 \%\right.$ S) soils; (c) $C_{v}$ values: RR-VD (25\% L + 75\% S) soils.

(a)

\begin{tabular}{cc}
\hline \multicolumn{2}{c}{ Co-efficient of consolidation $\boldsymbol{C}_{\boldsymbol{v}}$} \\
\hline Preload (kg) & $\boldsymbol{C}_{\boldsymbol{v}}$ \\
\hline 50 & 1.0380 \\
100 & 1.1331 \\
150 & 1.2415 \\
200 & 1.2813 \\
250 & 1.3224 \\
300 & 1.4770 \\
350 & 1.2966 \\
400 & 1.2035 \\
450 & 1.1946 \\
500 & 1.1673 \\
\hline
\end{tabular}

(b)

\begin{tabular}{cc}
\hline \multicolumn{2}{c}{ Co-efficient of consolidation $\boldsymbol{C}_{\boldsymbol{v}}$} \\
\hline Preload (kg) & $\boldsymbol{C}_{\boldsymbol{v}}$ \\
\hline 50 & 1.0379 \\
100 & 1.2812 \\
150 & 1.4602 \\
200 & 1.6798 \\
250 & 1.5103 \\
300 & 1.4600 \\
350 & 1.3661 \\
400 & 1.1326 \\
450 & 1.0994 \\
500 & 1.0681 \\
\hline
\end{tabular}

(c)

\begin{tabular}{cc}
\hline \multicolumn{2}{c}{ Co-efficient of consolidation $\boldsymbol{C}_{\boldsymbol{v}}$} \\
\hline Preload $(\mathbf{k g})$ & $\boldsymbol{C}_{\boldsymbol{v}}$ \\
\hline 50 & 1.0378 \\
100 & 1.3664 \\
150 & 1.8790 \\
200 & 1.9538 \\
250 & 1.5642 \\
300 & 1.5104 \\
350 & 1.4601 \\
400 & 1.2033 \\
450 & 1.1327 \\
500 & 1.0996 \\
\hline
\end{tabular}




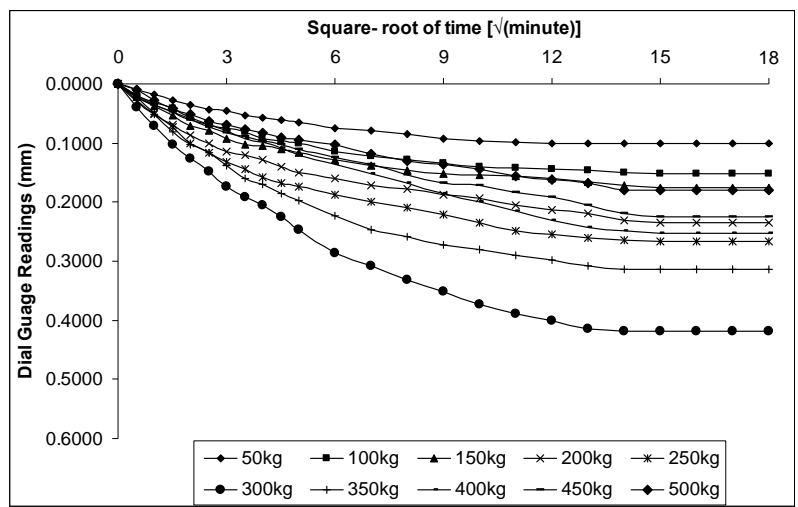

(a)

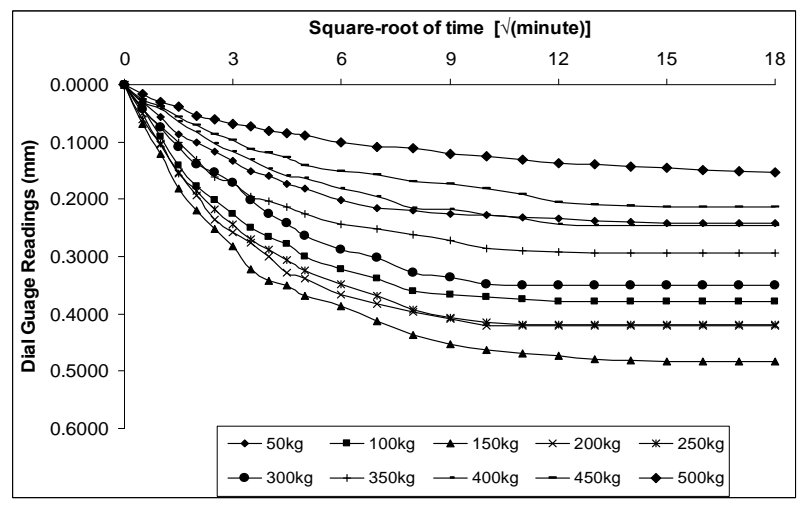

(b)

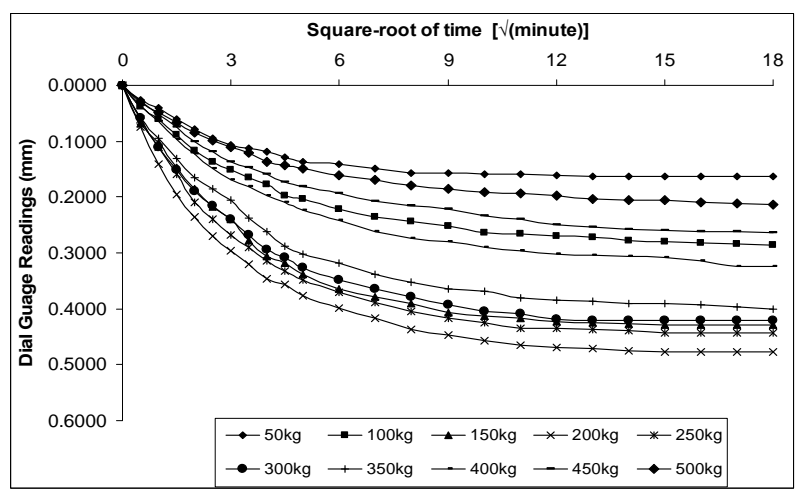

(c)

Figure 5. (a) Load-settlement: UR (25\% L + 75\% S) soils; (b) Load-settlement: UR-VD (25\% L + 75\% S) soils; (c) Load-settlement: RR-VD (25\% L + 75\% S) soils.

$250 \mathrm{~kg}$ to $500 \mathrm{~kg}$ shows a decreasing trend, indicating the commencement of the consolidation process.

\subsection{Soil Blend Type: $0 \%$ L $+100 \%$ S}

\subsubsection{Settlement for UR $(0 \% \mathrm{~L}+100 \% \mathrm{~S})$}

Figure 6(a) provides details on the load-settlement characteristics for un-reinforced soils comprising $100 \%$ shedi soil. Also, Table 5(a) provides details on the coefficient of consolidation $\left(C_{v}\right)$ for various preloads for the soil sample tested. Here, the compaction of soil is seen to have taken place up to preloads of $300 \mathrm{~kg}$. The rate of compaction for preloads of $350 \mathrm{~kg}$ to $500 \mathrm{~kg}$ shows a decreasing trend, indicating the commencement of the consolidation process.

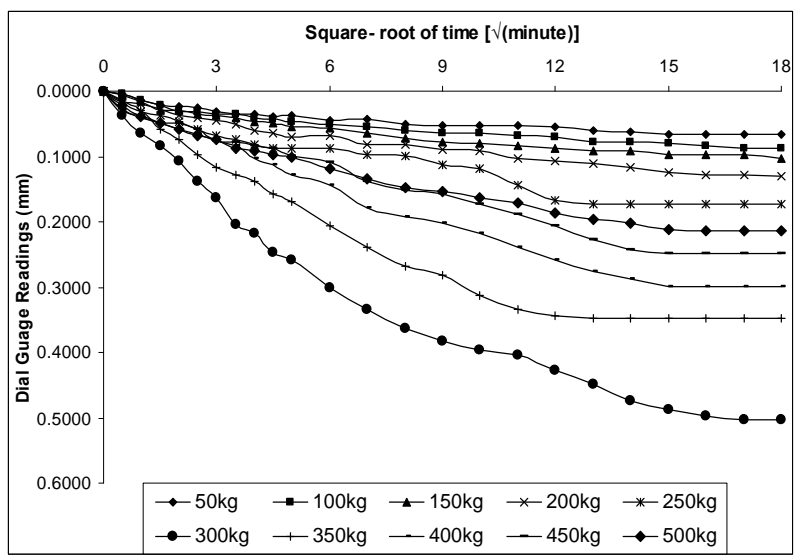

(a)

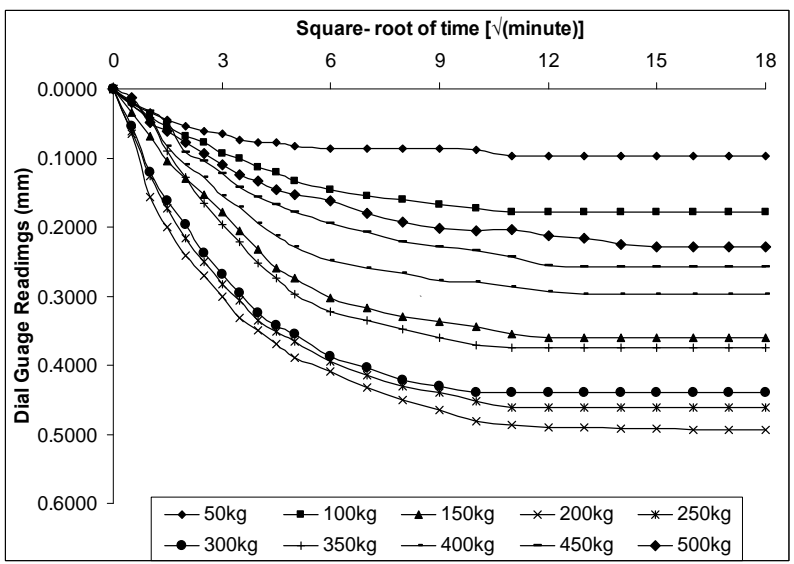

(b)

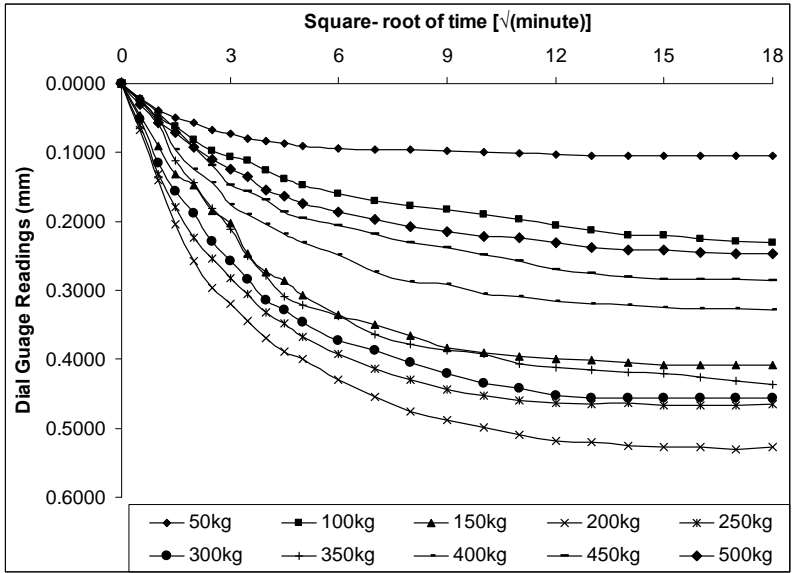

(c)

Figure 6. (a) Load-settlement: UR (0\% L + 100\% S) soils; (b) Load-settlement: UR-VD (0\% L + 100\% S) soils; (c) Load-settlement: RR-VD (0\% L + 100\% S) soils. 
Table 5. (a) $C_{v}$ values: UR $(0 \% \mathrm{~L}+\mathbf{1 0 0} \% \mathrm{~S})$ soils; (b) $C_{v}$ values: UR-VD (0\% L $+100 \% \mathrm{~S})$ soils; (c) $C_{v}$ values: RR-VD $(0 \% \mathrm{~L}+100 \% \mathrm{~S})$ soils.

(a)

\begin{tabular}{cc}
\hline \multicolumn{2}{c}{ Co-efficient of consolidation $\boldsymbol{C}_{\boldsymbol{v}}$} \\
\hline Preload (kg) & $\boldsymbol{C}_{\boldsymbol{v}}$ \\
\hline 50 & 1.0176 \\
100 & 1.0216 \\
150 & 1.0467 \\
200 & 1.0821 \\
250 & 1.1250 \\
300 & 1.4349 \\
350 & 1.2517 \\
400 & 1.2219 \\
450 & 1.1768 \\
500 & 1.1555 \\
\hline
\end{tabular}

(b)

\begin{tabular}{cc}
\hline \multicolumn{2}{c}{ Co-efficient of consolidation $\boldsymbol{C}_{\boldsymbol{v}}$} \\
\hline Preload (kg) & $\boldsymbol{C}_{\boldsymbol{v}}$ \\
\hline 50 & 1.0214 \\
100 & 1.1673 \\
150 & 1.3661 \\
200 & 1.5951 \\
250 & 1.4939 \\
300 & 1.4598 \\
350 & 1.3233 \\
400 & 1.1326 \\
450 & 1.0375 \\
500 & 1.0088 \\
\hline
\end{tabular}

(c)

\begin{tabular}{cc}
\hline \multicolumn{2}{c}{ Co-efficient of consolidation $\boldsymbol{C}_{\boldsymbol{v}}$} \\
\hline Preload (kg) & $\boldsymbol{C}_{\boldsymbol{v}}$ \\
\hline 50 & 1.0092 \\
100 & 1.3240 \\
150 & 1.8277 \\
200 & 1.8782 \\
250 & 1.5638 \\
300 & 1.5101 \\
350 & 1.4113 \\
400 & 1.2032 \\
450 & 1.0993 \\
500 & 1.0208 \\
\hline
\end{tabular}

\subsubsection{Settlement for UR-VD $(0 \% \mathrm{~L}+100 \% \mathrm{~S})$}

Figure 6(b) provides details on the load-settlement characteristics for un-reinforced vertically drained soils comprising 100\% shedi soil. Table 5(b) provides details on the coefficient of consolidation $\left(C_{v}\right)$ for various preloads. Here, the compaction of soil is seen to have taken place up to preloads of $200 \mathrm{~kg}$. The rate of compaction for preloads of $250 \mathrm{~kg}$ to $500 \mathrm{~kg}$ shows a decreasing trend, indicating the commencement of the consolidation process.

\subsubsection{Settlement for RR-VD $(0 \% \mathrm{~L}+100 \% \mathrm{~S})$}

Figure 6(c) provides details on the load-settlement characteristics for randomly-reinforced vertically drained soils comprising $100 \%$ shedi soil. Table 5(c) provides details on the coefficient of consolidation $\left(C_{v}\right)$ for various preloads. Here too, the compaction of soil is seen to have taken place up to preloads of $200 \mathrm{~kg}$ as in the case of UR-VD $(50 \% \mathrm{~L}+50 \% \mathrm{~S})$ and UR-VD $(25 \% \mathrm{~L}+75 \% \mathrm{~S})$ soils. The rate of compaction for preloads of $250 \mathrm{~kg}$ to $500 \mathrm{~kg}$ shows a decreasing trend, indicating the commencement of the consolidation process.

\section{Comparisons of Settlements of UR with UR-VD, and RR-VD Soils for Blends of Lateritic Lithomarge}

\subsection{UR vs UR-VD, and RR-VD: $50 \% \mathrm{~L}+\mathbf{5 0 \%} \mathrm{S}$ Soils}

Figure 7(a) provides details of the load-settlement trends for a preload of $50 \mathrm{~kg}$ for UR, UR-VD, and RR-VD test conditions for $50 \% \mathrm{~L}+50 \% \mathrm{~S}$ soils. Similar figures can be obtained and studied for preloads of $100 \mathrm{~kg}, 150 \mathrm{~kg}$, $200 \mathrm{~kg}, 250 \mathrm{~kg}, 300 \mathrm{~kg}, 350 \mathrm{~kg}, 400 \mathrm{~kg}, 450 \mathrm{~kg}$, and 500 $\mathrm{kg}$.

On observation of the load-settlement trends for various pre-loads, it was found that the 169th minute could be taken as a reference for comparison, since the soil was found to attain stability at this instance. In other words, the soil can be assumed to have been consolidated at this point in time.

The relative increase in consolidation achieved by unreinforced soil samples provided with vertical drains, when compared to un-reinforced soil samples without vertical drains is expressed using the percentage of the increase in settlement of the soil sample provided with vertical drains, to the settlement of the un-reinforced soil without vertical drains. This is denoted as, $R_{c t}(\mathrm{UR}$ v/s UR-VD).

Similarly, the relative increase in consolidation achieved by randomly reinforced soil samples provided with vertical drains, when compared to un-reinforced soil samples without vertical drains is expressed using the percentage of the increase in settlement of the randomly 
Table 6. (a) Relative increase in consolidation at different preloads at the 169thminute of L-S; (b) Relative increase in consolidation at different preloads at the 196th minute of L-S; (c) Relative increase in consolidation at different preloads at the 225th minute of L-S.

(a)

\begin{tabular}{ccc}
\hline $\begin{array}{c}\text { Preload } \\
(\mathbf{k g})\end{array}$ & $\begin{array}{c}\boldsymbol{R}_{c t}(\mathbf{U R} \text { vs UR-VD) } \\
\mathbf{( \% )}\end{array}$ & $\begin{array}{c}\boldsymbol{R}_{c t}(\mathbf{U R} \text { vs RR-VD) } \\
\mathbf{( \% )}\end{array}$ \\
\hline 50 & 38.61 & 64.64 \\
100 & 50.17 & 79.65 \\
150 & 65.16 & 87.33 \\
200 & 37.44 & 61.32 \\
250 & 02.12 & 15.44 \\
300 & 12.21 & 14.33 \\
350 & 14.25 & 31.13 \\
400 & 11.36 & 24.24 \\
450 & 08.22 & 18.53 \\
500 & 10.73 & 18.79 \\
\hline
\end{tabular}

(b)

\begin{tabular}{ccc}
\hline $\begin{array}{c}\text { Preload } \\
(\mathbf{k g})\end{array}$ & $\begin{array}{c}\boldsymbol{R}_{c t}(\mathbf{U R} \text { vs UR-VD) } \\
(\mathbf{\%})\end{array}$ & $\begin{array}{c}\boldsymbol{R}_{c t}(\mathbf{U R} \text { vs RR-VD) } \\
(\mathbf{\%})\end{array}$ \\
\hline 50 & 40.91 & 61.36 \\
100 & 59.95 & 85.15 \\
150 & 120.85 & 149.15 \\
200 & 102.52 & 106.43 \\
250 & 58.96 & 61.68 \\
300 & 5.20 & 13.98 \\
350 & 11.96 & 26.5 \\
400 & 18.29 & 24.32 \\
450 & 8.1 & 21.64 \\
500 & 15.1 & 24.25 \\
\hline
\end{tabular}

(c)

\begin{tabular}{ccc}
\hline $\begin{array}{c}\text { Preload } \\
\mathbf{( k g )}\end{array}$ & $\begin{array}{c}R_{c t}(\mathbf{U R} \text { vs UR-VD) } \\
\mathbf{( \% )}\end{array}$ & $\begin{array}{c}R_{c t}(\mathbf{U R} \text { vs RR-VD) } \\
\mathbf{( \% )}\end{array}$ \\
\hline 50 & 40.61 & 57.73 \\
100 & 120.49 & 172.84 \\
150 & 275.26 & 325.15 \\
200 & 294.55 & 321.6 \\
250 & 152.02 & 168.44 \\
300 & 5.95 & 15.33 \\
350 & 7.37 & 20.40 \\
400 & 4.01 & 18.69 \\
450 & 7.98 & 17.65 \\
500 & 13.06 & 20.10 \\
\hline
\end{tabular}

reinforced soil sample provided with vertical drains, to the settlement of the un-reinforced soil without vertical drains. This is denoted as, $R_{c t}$ (UR vs RR-VD).

Table 6(a) provides details on the relative increase in consolidation at different preloads at the 169th minute of the load settlements for UR v/s UR-VD, and UR v/s RR-VD observations. In this table, it is observed that for pre-loads ranging from $50 \mathrm{~kg}$ to $200 \mathrm{~kg}$, the effect of providing vertical drains was significant when compared to the rate of settlement in the case of UR soils. The $R_{c t}$ (UR $\mathrm{v} / \mathrm{s}$ UR-VD) values within this range of pre-loads vary from $37.14 \%$ to $65.29 \%$. But for pre-loads higher than $200 \mathrm{~kg}$, the effect of providing vertical sand drains was not significant as it was found to vary between $2.13 \%$ to $14.35 \%$.

Also, for the pre-loads ranging from $50 \mathrm{~kg}$ to $200 \mathrm{~kg}$, the effect of randomly reinforcing the soil was significant when compared to the rate of settlement in the case of UR soils. The $R_{c t}$ (UR v/s RR-VD) values were found to range between $60.12 \%$ to $86.13 \%$, whereas for pre-loads greater than $200 \mathrm{~kg}$, the increase was found to be moderate with $R_{c t}$ (UR v/s RR-VD) values ranging between $14.33 \%$ to $31.04 \%$.

Therefore, it can be seen that the combined effect of vertical drains and random reinforcement with coir fibers resulted in considerable increase in the rate of consolidation at lower pre-loads.

\subsection{UR vS UR-VD, and RR-VD: $25 \% \mathrm{~L}+\mathbf{7 5 \%} \mathrm{S}$ Soils}

Figure 7(b) provides details of the load-settlement trends for a preload of $50 \mathrm{~kg}$ for UR, UR-VD, and RR-VD test conditions for $50 \% \mathrm{~L}+50 \% \mathrm{~S}$ soils. Similar figures can be obtained and studied for preloads of $100 \mathrm{~kg}, 150 \mathrm{~kg}$, $200 \mathrm{~kg}, 250 \mathrm{~kg}, 300 \mathrm{~kg}, 350 \mathrm{~kg}, 400 \mathrm{~kg}, 450 \mathrm{~kg}$, and 500 $\mathrm{kg}$.

On observation of the load-settlement trends for various pre-loads, it was found that the 169th minute could be taken as a reference for comparison, since the soil was found to attain stability at this instance.

Table 6(b) provides details on the relative increase in consolidation at different preloads at the 169th minute of the load settlements for $U R \mathrm{~V} / \mathrm{s}$ UR-VD, and UR v/s RR-VD observations. In this table, it is observed that for pre-loads ranging from $50 \mathrm{~kg}$ to $250 \mathrm{~kg}$, the effect of providing vertical drains was significant when compared to the rate of settlement in the case of UR soils. The $R_{c t}$ (UR $\mathrm{v} / \mathrm{s}$ UR-VD) values within this range of pre-loads vary from $40.91 \%$ to $120.85 \%$. But for pre-loads higher than $200 \mathrm{~kg}$, the effect of providing vertical sand drains was insignificant as it varied between $5.2 \%$ and $18.29 \%$.

Also, for the pre-loads ranging from $50 \mathrm{~kg}$ to $250 \mathrm{~kg}$, the effect of randomly reinforcing the soil was significant 


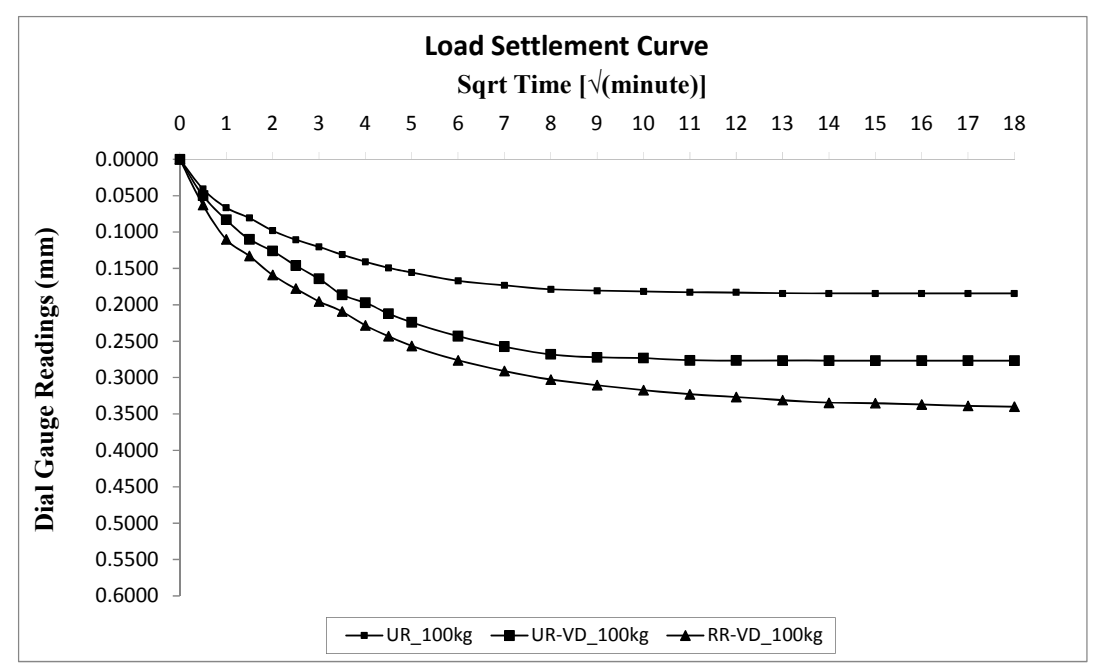

(a)

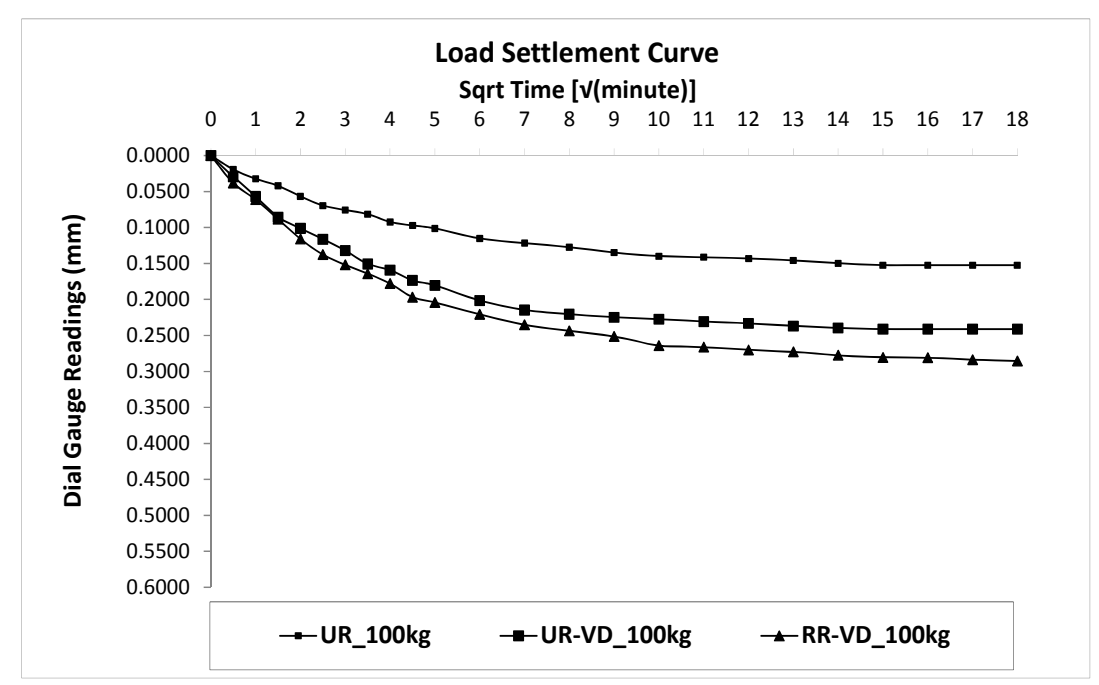

(b)

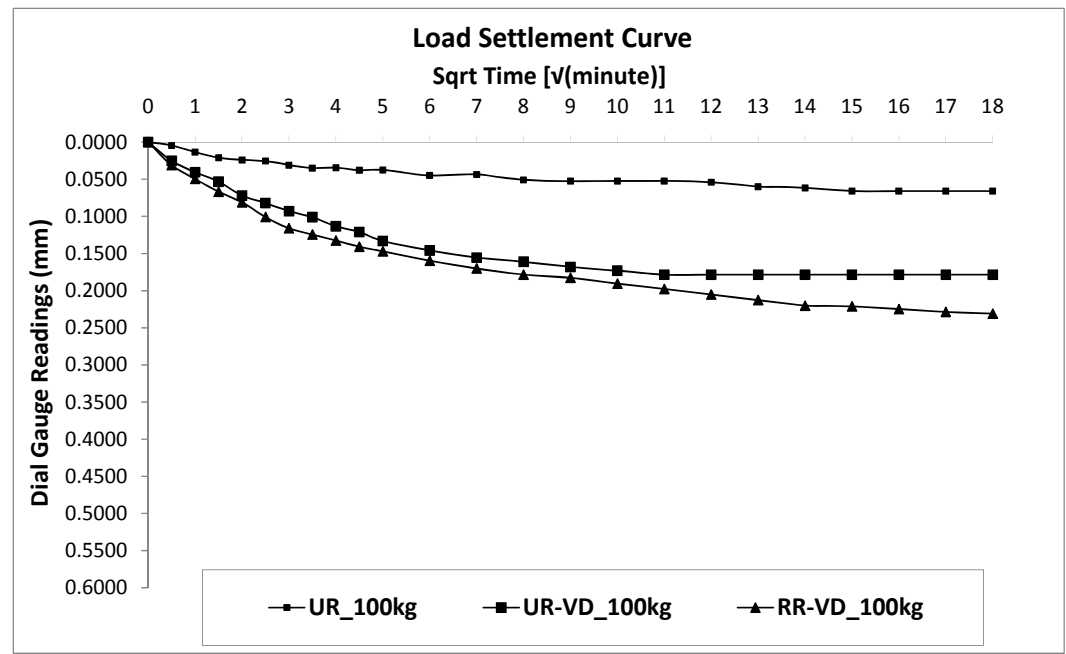

(c)

Figure 7. (a) Load-settlement trend for preload of $100 \mathrm{~kg}$ for $50 \% \mathrm{~L}+\mathbf{5 0 \%} \mathrm{S}$ soil; (b) Load-settlement trend for preload of $100 \mathrm{~kg}$ for $25 \% \mathrm{~L}+75 \% \mathrm{~S}$ soil; (c) Load-settlement trend for preload of $100 \mathrm{~kg}$ for $0 \% \mathrm{~L}+100 \% \mathrm{~S}$ soil. 
when compared to the rate of settlement in the case of UR soils. The $R_{c t}$ (UR v/s RR-VD) values were found to range from $61.36 \%$ to $149.15 \%$, whereas for pre-loads greater than $250 \mathrm{~kg}$, the increase was found to be moderate with $R_{c t}$ (UR v/s RR-VD) values ranging from $13.98 \%$ to $24.32 \%$.

Therefore, it can be seen that the combined effect of vertical drains and random reinforcement with coir fibers resulted in considerable increase in the rate of consolidation at lower pre-loads.

\subsection{UR vs UR-VD, and RR-VD: $0 \% \mathrm{~L}+100 \% \mathrm{~S}$ Soils}

Figure 7(c) provides details of the load-settlement trends for a preload of $50 \mathrm{~kg}$ for UR, UR-VD, and RR-VD test conditions for $50 \% \mathrm{~L}+50 \% \mathrm{~S}$ soils. Similar figures can be obtained and studied for preloads of $100 \mathrm{~kg}, 150 \mathrm{~kg}$, $200 \mathrm{~kg}, 250 \mathrm{~kg}, 300 \mathrm{~kg}, 350 \mathrm{~kg}, 400 \mathrm{~kg}, 450 \mathrm{~kg}$, and 500 $\mathrm{kg}$.

On observation of the load-settlement trends for various pre-loads, it was found that the 225th minute could be taken as a reference for comparison, since the soil was found to attain stability at this instance.

Table 6(c) provides details on the relative increase in consolidation at different preloads at the225th minute of the load settlements for UR v/s UR-VD, and UR v/s RR-VD observations. In this table, it is observed that for pre-loads ranging from $50 \mathrm{~kg}$ to $250 \mathrm{~kg}$, the effect of providing vertical drains was significant when compared to the rate of settlement in the case of UR soils. The $R_{c t}$ (UR v/s UR-VD) values within this range of pre-loads vary from $40.61 \%$ to $294.55 \%$. But for pre-loads higher than $200 \mathrm{~kg}$, the effect of providing vertical sand drains was not significant as it was found to vary between $4.01 \%$ and $13.06 \%$.

Also, for the pre-loads ranging from $50 \mathrm{~kg}$ to $250 \mathrm{~kg}$, the effect of randomly reinforcing the soil was significant when compared to the rate of settlement in the case of $U R$ soils. The $R_{c t}$ (UR v/s RR-VD) values were found to range from $57.73 \%$ to $325.15 \%$, whereas for pre-loads greater than $250 \mathrm{~kg}$, the increase was found to be moderate with $R_{c t}$ (UR v/s RR-VD) values ranging from $15.33 \%$ to $20.40 \%$.

Therefore, it can be seen that the combined effect of vertical drains and random reinforcement with coir fibers resulted in considerable increase in the rate of consolidation at lower pre-loads, whereas a moderate increase was observed at higher pre-loads.

\section{Conclusions}

The above sections focused on examining the rate of consolidation for various types of soil mixes for various test conditions using vertical drains. The observations made as part of this work will have an important bearing on the construction of road and railway embankments on lateritic soil sub-grades.

Also, natural fibers of coir can be effectively used in further accelerating consolidation since the fibers allow pore-water pressures to dissipate easily when subjected to overburden pressures. Also, coir, being a natural fiber, undergoes decomposition once the soil attains sufficient strength through consolidation.

Laboratory investigations were performed in this study, for soil compacted in cylindrical moulds of $70 \mathrm{~cm}$ diameter and $85 \mathrm{~cm}$ internal height for laterite soil blended with $50 \%$ shedi soil $(50 \% \mathrm{~L}+50 \% \mathrm{~S})$, laterite soil blended with $75 \%$ shedi soil $(25 \% \mathrm{~L}+75 \% \mathrm{~S})$ and shedi soil $(0 \%$ $\mathrm{L}+100 \% \mathrm{~S}$ ). Tests on drained soil samples were performed by providing 3 vertical sand drains reinforced with $1 \%$ coir fiber. The following are the conclusions drawn from this study.

\subsection{Soil Type: $50 \% \mathrm{~L}+50 \% \mathrm{~S}$}

From Sections 8.1 and 9.1, and Table 6(a), it is seen that the $50 \% \mathrm{~L}+50 \% \mathrm{~S}$ soil type attained stability at around the 169th minute after application of the preloads. Using this as datum, it can be observed that for the pre-loads ranging from $50 \mathrm{~kg}$ to $200 \mathrm{~kg}$, the effect of randomly reinforcing the soil was significant when compared to the rate of settlement in the case of UR soils. The relative increase in settlement of $R R-V D$ soils when compared to that of UR soils $\left(R_{c t}\right.$ (UR v/s RR-VD)), was found to range between $60.12 \%$ to $86.13 \%$, with an average increase of $71.73 \%$, whereas for pre-loads greater than 200 $\mathrm{kg}$, the increase was found to be moderate with $R_{c t}$ (UR $\mathrm{v} / \mathrm{s}$ RR-VD) values ranging between $14.13 \%$ to $31.04 \%$, with an average increase of $20.51 \%$. Considering the average values, for pre-loads ranging from $50 \mathrm{~kg}$ to 200 $\mathrm{kg}$, there is an additional increase of $24.8 \%$ in the settlement of randomly reinforced soil blends when compared to that of soil blends with vertical drains alone. Hence it can be concluded that in the soil blend of $50 \% \mathrm{~L}+50 \% \mathrm{~S}$, there is a significant increase in settlement due to random reinforcement with coir fibers in addition to the vertical drains.

\subsection{Soil Type: $25 \%$ L $+75 \%$ S}

From Sections 8.2 and 9.2, and Table 6(b), it is seen that the $25 \% \mathrm{~L}+75 \% \mathrm{~S}$ soil type attained stability at around the 196th minute after application of the preloads. Using the same 196th minute as datum, it can be observed that for the pre-loads ranging from $50 \mathrm{~kg}$ to $250 \mathrm{~kg}$, the effect of randomly reinforcing the soil in addition to providing vertical sand drains, was significant when compared to 
the rate of settlement in the case of UR soils. The relative increase in settlement of RR-VD soils when compared to that of UR soils $\left(R_{c t}(\mathrm{UR}\right.$ v/s RR-VD)), was found to range between $61.36 \%$ and $149.15 \%$, with an average increase of $92.7 \%$, whereas for pre-loads greater than $150 \mathrm{~kg}$, the increase was found to be moderate, with $R_{c t}$ (UR v/s RR-VD) values ranging between $13.98 \%$ to $24.32 \%$ with an average increase of $22.1 \%$. Considering the average values, for pre-loads ranging from $50 \mathrm{~kg}$ to $250 \mathrm{~kg}$, there is an additional increase of $16.1 \%$ in the settlement of randomly reinforced soil blends when compared to that of soil blends with vertical drains alone. Hence it can be said that for the soil blend of $25 \% \mathrm{~L}+$ $75 \% \mathrm{~S}$, there is a significant increase in settlement due to random reinforcement with coir fibers in addition to the vertical drains.

\subsection{Soil Type: $0 \% \mathrm{~L}+100 \% \mathrm{~S}$}

From Sections 8.3 and 9.3, and Table 6(c), it is seen that the $0 \% \mathrm{~L}+100 \% \mathrm{~S}$ soil type attained stability at around the 225th minute after application of the preloads. The 225 th minute is taken as a reference since the graphical trends indicate that for the pre-loads ranging from $50 \mathrm{~kg}$ to $250 \mathrm{~kg}$, the effect of randomly reinforcing the soil in addition to providing vertical sand drains, was significant when compared to the rate of settlement in the case of UR soils. The relative increase in settlement of RR-VD soils when compared to that of UR soils $\left(R_{c t}(\mathrm{UR} \mathrm{v} / \mathrm{s}\right.$ RR-VD)), was found to range between $57.73 \%$ and $325.15 \%$, with an average increase of $209.1 \%$, whereas for pre-loads greater than $250 \mathrm{~kg}$, the increase was found to be moderate, with $R_{c t}(\mathrm{UR} \mathrm{v} / \mathrm{s} \mathrm{RR}-\mathrm{VD})$ values ranging between $15.33 \%$ to $20.4 \%$ with an average increase of $18.43 \%$. Considering the average values, for pre-loads ranging from $50 \mathrm{~kg}$ to $250 \mathrm{~kg}$, there is an additional increase of $32.6 \%$ in the settlement of randomly reinforced soil blends when compared to that of soil blends with vertical drains alone. Hence it can be concluded that in the soil blend of $0 \% \mathrm{~L}+100 \% \mathrm{~S}$, there is a significant increase in settlement due to random reinforcement with coir fibers in addition to the vertical drains.

\section{REFERENCES}

[1] F. Buchanan, "A Journey from Madras through the Countries of Mysore, Canara and Malabar," Asian Educational Services, New Delhi, 1807.

[2] K. Balan, "Studies on Engineering Behavior and Uses of Geo-Textiles with Natural Fibers," Ph.D. Thesis, Indian Institute of Technology Delhi, New Delhi, 1995.

[3] Santosh, "A Model Study on Accelerated Consolidation of Coir Reinforced Laterite and Blended Shedi Soil with Vertical Sand Drains for Pavement Foundations," M.Tech. Thesis, National Institute of Technology Karnataka, Surathkal, 2010.

[4] L. D. Prashanth, "Studies on Accelerated Consolidation of Coir Reinforced Laterite and Shedi Soil with Vertical Sand Drains for Pavement Foundations," M.Tech. Thesis, National Institute of Technology Karnataka, Surathkal, 2010 .

[5] J. O. Akinumusura and J. A. Akinbolade, "Stability of Loaded Footings on Reinforced Soil," Journal of Geotechnical and Geoenvironmental Engineering, Vol. 107, No. 6, 1981, pp. 819-827.

[6] S. L. Lee, G. P. Karunaratne, N. C. Dasgupta, S. D. Ramaswamy and M. A. Aziz, "A Vertical Drain Made of Natural Fiber for Soil Improvement Projects," Proceedings of International Workshopon Geotextiles, Bangalore, 1989, pp. 271-276.

[7] H. D. Charan, G. Ranjan and R. M. Vasan, "Strength Characteristics of Coir Fibers Reinforced Sand," Proceeding Indian Geotechnical Conference, Bangalore, December 1995, pp. 339-342.

[8] J. N. Mandal and M. V. R. Murthi, "Potential Use of Natural Fibers in Geotechnical Engineering," Proceedings of International Workshopon Geotextiles, Bangalore, 22-29 November 1989, pp. 251-254.

[9] T. Stapelfeldt, "Preloading and Vertical Drains," 2006. http://wwwtkk.fi/Yksikot/Rakennus/Pohja/Preloading_an d_vertical_drains.pdf

[10] D. T. Bergado, A. S. Enriquez, C. L. Sampaco, M. C. Alfaro and A. S. Balasubramaniam, "Inverse Analysis of Geotechnical Parameters on Improved Soft Bangkok Clay," Journal of Geotechnical Engineering Journal of Geotechnical Engineering, Vol. 118, No. 7, 1992, pp. 1012-1030.

[11] M. Gosavi, K. A. Patil and S. Mittal, "Improvement of Properties of Black Cotton Soil Sub-Grade through Natural Reinforcement," Proceeding of Indian Geotechnical Conference, Roorkee, 18-20 December 2003, pp. 379383.

[12] K. Terzaghi, Erbaumechanik auf Bodenphysi-kalisher Grundlagen, Deuticke, Vienna, Austria (in German), 1923.

[13] K. Terzaghi, "Theoretical Soil Mechanics," John Wiley \& Sons, Inc., New York, 1943. doi:10.1002/9780470172766

[14] S. K. Khanna and C. E. G. Justo, "Highway Engineering," Nem Chand \& Bros, Roorkee, 2001.

[15] G. Venkatappa Rao, R. K. Dutta and D. Ujwala, "Strength Characteristics of Sand Reinforced with Coir Fibers and Coir GeoTextiles," Electronic Journal of Geo- technical Engineering, Vol. 10, 2005. http://www.ejge.com/2005/ JourTOC10G.htm

[16] Bureau of Indian Standards, "Indian Standard Methods of Tests for Soils, Part XVI, Laboratory Determination of CBR,” Bureau of Indian Standards, New Delhi, 1987. 